\title{
Influence of National Essential Public Health Services Policy on Expenditure for Hypertension in China: A Difference-in-Difference Analysis
}

\section{Long Xue ( $\sim 23457488 @ q q . c o m)$}

Fudan University School of Public Health https://orcid.org/0000-0003-1856-9281

Mengyun Sui

Fudan University

\section{YunZhen He}

Fudan University

Hongzheng Li

Fudan University

\section{Ziyan Liu}

Fudan University

\section{Huilin Sheng}

Putuo Maternity and Infant Hospital

\section{Xiaohua Ying}

Fudan University

\section{Research}

Keywords: hypertension, expenditure, effectiveness, evaluation, public policy, prevention

Posted Date: August 5th, 2021

DOI: https://doi.org/10.21203/rs.3.rs-777711/v1

License: (1) This work is licensed under a Creative Commons Attribution 4.0 International License. Read Full License 


\section{Abstract}

Background: The prevention and control of hypertension should be an effective way to reduce deaths and it has been a high priority in China. The Chinese government issued the National Essential Public Health Services Package (NEPHSP) in 2009; this initiative provides free public health services to meet the challenges posed by hypertension. It includes health education, regular health checkups, and regular follow-ups provided to patients with hypertension aged $\geq 35$. This study explored the influence of the NEPHSP on outpatient and inpatient expenditure among patients with hypertension.

Methods: Data were mined from the 2011-2015 Harmonized China Health and Retirement Longitudinal Study. The dependent variables were the outpatient and inpatient expenditure of patients with hypertension. The independent variable was defined as whether covered by the NEPHSP in 2013 or 2015 . Using propensity score matching (PSM) to match the individual characteristics of hypertension in the NEPHSP-covered group and the NEPHSP-uncovered group, Tobit regression models with difference-in-differences (DID) were used to analyze the outcomes.

Results: After PSM, of the 1,956 hypertensive participants, 369 had physical exams covered by the NEPHSP in 2013 and 2015. In 2013 and 2015, the outpatient and inpatient expenses of patients with hypertension increased compared with 2011. A DID estimate for the NEPHSP-covered service was associated with a marginal significant decrease of RMB $319.79(p=0.586)$ and RMB $1072.02(p=0.068)$ in hypertension inpatient expected expenditure in 2013 and 2015, respectively. The DID estimate showed no significant change among outpatient expected expenditure.

Conclusions: The NEPHSP may reduce inpatient expenditure among patients with hypertension. Further strengthening of the NEPHSP may reduce their burden.

\section{Background}

Two recent studies of hypertension in China suggest that the incidence of hypertension in China was $23.2 \%$ among people aged $\geq 18$ and over [1], and 44.7\% among people aged 35-75 [2]. Moreover, hypertension increased from $18 \%$ [3] to $23.2 \%$ from 2002 to 2015 . However, several studies on hypertension in China indicate that less than $50 \%$ of patients were aware of their condition, $30-40 \%$ were taking prescribed antihypertensive medications, and $7.2-15.3 \%$ had achieved control $[1,2,4]$. For example, using the same nationwide survey from the Chinese studies [1] but applying the 2017 American College of Cardiology/American Heart Association Guidelines for high blood pressure, hypertension incidence in China reached $46.4 \%$, while the blood pressure control rate dropped to $3.0 \%$.

Cardio-cerebrovascular diseases caused by untreated and inadequately treated hypertension have been the main cause of death among Chinese people [5]. As prevention and control of hypertension should be an effective way to reduce deaths [6], it has been a high priority in China [7]. The Chinese government issued the National Essential Public Health Services Package (NEPHSP) in 2009; this initiative provides free public health services to meet the challenges posed by hypertension. It includes health education, regular health checkups, and regular follow-ups provided to patients with hypertension aged $\geq 35$ [8] (see Additional Table 1 for details). At inception, citizens received public health subsidies of RMB 15 from the government, which increased to RMB 25, RMB 30, and RMB 
40 in 2011, 2013, and 2015, respectively. The government increased support for patients with hypertension from $\geq 45$ million in 2011, to $\geq 70$ million in 2013, and more than 80 million in 2015 [9,10].

Previous studies have indicated that the number of patients with hypertension covered by the NEPHSP is positively associated with hypertension control rates, medication rates, and blood pressure monitoring rates $[11,12]$. However, no studies have investigated whether higher rates of medication and blood pressure monitoring are associated with higher costs for hypertension treatment. Further, previous studies on the cost of hypertension treatment did not include the effect of the NEPHSP [13-15].

In this study, we used nationally representative longitudinal data to analyze 1) the changes and differences in outpatient and inpatient expenses of hypertensive patients before and after the NEPHSP was implemented and 2) the impact of the NEPHSP on outpatient and hospitalization costs of hypertensive patients.

\section{Methods}

\subsection{Data and sample}

Data were obtained from the China Health and Retirement Longitudinal Study (CHARLS), a nationally representative survey of individuals aged $\geq 45$ that is administered every two years since 2011 . The data included 17,708 participants distributed across 450 villages in 150 counties [16]. For cross-national comparisons of other international aging surveys, a Harmonized CHARLS was created to coordinate the CHARLS with the Health and Retirement Survey in the United States, for which detailed information is publicly available online [17].

Patients with hypertension were defined as respondents who self-reported high blood pressure in 2011 and were not covered by the NEPHSP in that year (hereafter, NEPHSP-uncovered). The final data set included 3,192 hypertensive patients who were not lost to follow-up and had no significant variables missing in 2011, 2013, and 2015 (Figure 1). This study reported the direct spending of outpatients and inpatients separately and used the data as the dependent variable in the models. All outpatient expenditure in the past month was recorded, including both treatment and medication costs. Direct medical costs were included in inpatient expenditures during the past year, while indirect medical costs were excluded. To identify total hospitalization expenditure in the past year, total medical cost of doctor visits, and amount paid by their insurance company, we used the following items from the CHARLS baseline questionnaire: "How many times have you received inpatient care?," "How many times did you visit a medical facility?," "What is your total hospitalization cost?," and "What is your total outpatient cost?" If the respondent had two or more inpatient or outpatient treatments in the past year or month, then the respondent was asked to list the total medical costs for all visits.

The essential independent variable was the NEPHSP-covered participants. To determine whether hypertensive patients were covered by NEPHSP, we used the question "When did you have your last physical examination?" to identify responders who had received physical exams in 2011, 2013, or 2015. The question "Who paid for your last physical examination?" measured whether the medical costs were covered by the NEPHSP, given that the NEPHSP includes a free physical exam at least once a year for patients with hypertension aged $\geq 35$.

Respondents who chose "government" were the treatment group, and respondents who chose "non-government" had not received a free medical exam and were defined as the comparison group. 
The covariate variables for this study consisted of individual socioeconomic characteristics and health information, such as age ( $\geq 65$ or not), sex (male or female), marital status (living with or without a partner), occupation (farmer or not), education ( 1 = Less than lower secondary education, 2 = Elementary school, and $3=$ Middle school). Household income classified by quartiles into four groups: poor (< RMB 3,335), low income (RMB 3,335-17,200), middle income (RMB 17,200-40,965), and high income ( $\geq$ RMB 40,965). Other characteristics were insurance (have or not), overweight and obesity (body mass index [BMI] $\geq 24.0$ or not) [18], and self-reported health status (not poor or poor).

\subsection{Statistical analysis}

As indicated above, respondents covered by NEPHSP between 2013 and 2015 were defined as the treatment group, while the comparison group had not received this service. First, we found a gap in the socioeconomic and health characteristics between the two groups of hypertensive patients. The covariates of the two groups of hypertensive patients in 2011 were matched by propensity score matching (PSM) [18], which enables us to calculate weights based on the socioeconomic characteristics and health information of patients with hypertension that yield unbiased estimates of the impact of factors of interest [19]. We adopted the 1:4 neighbor matching method to match the treatment and comparison groups and retained the matched data for the final analysis.

Second, based on the matched data, a difference-in-differences (DID) method was used to analyze healthcare expenditure changes from before the NEPHSP (2011) compared to after (2013 and, separately, 2015). DID can effectively detect the intervention effect between the treatment and comparison groups and isolate the time trend unrelated to the intervention [20]. The effect of the NEPHSP is estimated by comparing the differences between two changes in outcomes: (1) changes between pre-and post-NEPHSP within the treatment group and (2) the preand post-intervention periods in the comparison group [21]. Given that the skewed distribution of health cost data (which contain many zero values) violated the normal distribution assumption of the ordinary linear model, a Tobit model is suitable for the analysis [22]. Therefore, a panel data Tobit regression model was employed for continuity outcomes to estimate NEPHSP's effect on each group's healthcare expenditure. More than 50\% of the cost of patients with hypertension in our sample has a value of 0 , and the values that are not 0 conform to the normal distribution; we reported the mean value when describing the sample. A P-value $<0.1$ was considered statistically significant. All analyses were performed using Stata software, version 16.

\subsection{Ethical approval}

All participants provided written informed consent and ethical approval for collecting data on human subjects was obtained from the appropriate Biomedical Ethics Review Committee.

\section{Results}

\subsection{Sample characteristics}

Additional Table 2 presents the socioeconomic and health characteristics $(N=3,192)$ for each group. Compared with 2011, the proportion of patients with hypertension who were aged $\geq 65$, poor-house-income, BMI $\geq 24$, and good self-reported health increased in 2015 for both groups, while having a partner, farmers, having insurance, 
and low middle high-house-income declined in 2015. The sex, marriage, education, and residence status of the patients with hypertension remained constant for both groups.

\subsection{Baseline characteristics after PSM}

Table 1 illustrates the socioeconomic and health characteristics before and after the PSM in 2011. Before matching, the samples differed significantly in terms of age, elementary school education, middle school education, and high income. After matching, the differences in the socioeconomic and health characteristics between the two groups became insignificant.

Additional files Figure 1, Figure 2, Figure 3, and Figure 4 illustrate the standardized bias across the covariates in the $-10 \%$ to $10 \%$ range, propensity score distribution, and kernel density across the two groups' propensity scores before and after matching, and the matching effect was satisfactory.

\subsection{Healthcare expenditure changes pre- and post-NEPHSP}

Figure 2 and Figure 3 presents the patients with hypertension' outpatient and inpatient expenditure patterns with and without the NEPHSP before and after PSM from 2011 vs. 2015. Outpatient and inpatient expenses of the treatment group and comparison group before and after matching increased in 2013 and 2015 compared with 2011.

\subsection{Common trend assumption}

Figure 4 illustrates the expenditure of outpatients and inpatients, compared between the comparison and treatment groups in pre-and post-intervention, respectively, after PSM. No statistically significant differences for the outpatient and inpatient expenses in the pre-intervention period estimates were observed; outpatient and inpatient expenditure was also not statistically significant at the post-intervention period.

\subsection{Comparing the treatment group and the comparison group}

Table 2 presents the Tobit regression results from the DID analyses of outpatient and inpatient expenditure changes between treatment and comparison groups after PSM. Compared to 2011, the treatment group was associated with an increase in outpatient expenditure in 2013 and a decrease in 2015. In terms of inpatient expenditure, outcomes did not change in 2013; however, in 2015, the treatment group was associated with a marginal significant decrease of -1072.02 in inpatient expected expenditure, a decrease of 426.40 in inpatient expenditure more than 0, and a decrease of 599.73 in inpatient actual expenditure, both compared with 2011.

\section{Discussion}

Our results revealed that the inpatient expenditure of patients with hypertension decreased after the expanded NEPHSP was implemented in 2015. Previous research indicates that expanded NEPHSP implementation could improve the rate of hypertension control, antihypertensive medication use, and blood pressure monitoring [11]. Other research has indicated that providing free public health services to patients with hypertension can effectively reduce their burden [23]. The NEPHSP may have a positive influence that is related to improvements in hypertension diagnosis, treatment, and control. Indeed, some signs point to a shift toward reactive care for prevention [24], which may be positively correlated with promoting healthy lifestyle traits, such as a low sodium 
diet [25], physical activity, weight loss, and smoking and drinking cessation [26]. It may also signal decreases in hospitalization rates, lengths of stay, or procedures for complications [27]. The NEPHSP provides free preventive care services for patients with hypertension to prevent or delay comorbidity and complications of the disease and lower overall healthcare costs. These results are similar to those of a study conducted in Japan that demonstrated that free screening and treatment services for patients with hypertension were associated with a $42-75 \%$ reduction in stroke incidence [28]. Thus, it is not surprising that in China, the expanded NEPHSP can reduce the disease burden of patients with hypertension.

There was an overall upward trend in expenditure associated with hypertension from 2011 to 2015, which might be related to the increasing incidence of hypertension in China. China is one of the fastest growing countries all over the world [29], the prevalence of self-reported hypertension among people aged 15 and over rose from $6.7 \%$ in 2008 to $14.2 \%$ in 2013. Meanwhile, the number of patients with hypertension older than 65 increased from $21.6 \%$ to $37 \%$ and the number of patients with hypertension aged 45 to 64 also doubled during this period [30]. The life expectancy of patients with hypertension and incidence of young hypertensive patients increased. Correspondingly, healthcare expenditure increased, as people with hypertension live longer and their chances of developing comorbidities and complications increase [26,31]. One study in China revealed that $87 \%$ of heart disease deaths, $71 \%$ of stroke deaths, $54 \%$ of ischemic heart disease deaths, $41 \%$ of other cardiovascular disease deaths, and $43 \%$ of chronic kidney disease deaths were attributable to hypertension [32], which may also be one of the reasons for the increased cost for patients with hypertension observed in this study.

We noted that healthcare costs for patients with high blood pressure increased more slowly in the two groups after 2013. This may be related to improved health literacy among patients with hypertension, or it could be due to "spillover effects" from the NEPHSP. The same spillover effects have been observed in other policy studies [33,34]. Our results suggest that there might be a positive spillover effect between the treatment group and the comparison group, but a negative spillover effect between the expenditure of outpatients and inpatients.

After 2013, the outpatient and inpatient expenditure of patients with hypertension who were not covered by the NEPHSP rose slowly. Those covered by the NEPHSP displayed a slow upward tendency in outpatient services and a downward tendency in hospitalization services. These findings suggest that the implementation of the NEPHSP might be achieving its goals of improving hypertension management. The same results have been confirmed in other studies in China $[11,35]$. Compared with 2002, the number of patients who were aware they had hypertension increased by 54 million, the number who were treated increased by 53 million, and the number whose blood pressure was under control increased by 0.25 million. This is largely because of the government's continued efforts to reform the healthcare system and equalize public health services.

We acknowledge that there are several limitations to this study. First, although PSM was used to eliminate some individual selection bias factors, there are numerous confounding factors, such as the living environment, social network, access to health care in the place of residence, medical consumer price level, and healthcare supply in the place of residence. Second, our dependent variable fails to isolate the costs purely because of hypertension, and other comorbidities of the patients with hypertension may interfere with the results. Future studies must link the survey data and the medical treatment data to obtain the pure cost of hypertension. Moreover, there was a considerable amount of zero values in the dependent variable, which, despite the use of the Tobit model, may still affect the result estimates, as we cannot determine whether the cost is due to patient visits or non-visits to healthcare providers. Finally, we used data for patients with hypertension aged 45 and over in the CHARLS, but 
patients with hypertension aged 35 and over were covered by the NEPHSP, which may have influenced our estimates. In the future, we will use more nationally representative samples and include more variables to study this issue.

\section{Conclusions}

In China, the implementation of the NEPHSP may have reduced the healthcare expenditure of patients with hypertension. This may be due to guidance for patients with hypertension to regularly visit their doctor, improve medication and control, or reduce complications and hospitalization. The NEPHSP is an important health policy that encourages patients with hypertension to seek medical care reasonably and regularly. In the future, financial compensation should be increased, the catalog of free screening services for chronic diseases should be expanded, the occurrence of chronic disease complications should be avoided or delayed, and the burden of chronic diseases should be reduced. For policymakers, the NEPHSP may have begun to achieve its goals of increasing the health awareness of patients with hypertension and reducing their financial burden.

\section{List Of Abbreviations}

National Essential Public Health Services Package (NEPHSP)

China Health and Retirement Longitudinal Study (CHARLS)

Body mass index (BMI)

propensity score matching (PSM)

difference-in-differences (DID)

\section{Declarations}

Ethics approval and consent to participate: All participants provided written informed consent, and ethical approval for collecting data on human subjects was obtained from the Biomedical Ethics Review Committee of Peking University (IRB00001052-11015).

Consent for publication: Not applicable

Availability of data and materials: The datasets used and/or analyzed during the current study are available from the corresponding author on reasonable request.

Competing interests: The authors declare that they have no competing interests.

Funding: This research received no external funding

Authors' contributions: L.X. Y.Z., and X.H. contributed to the conceptualization and study design. L.X., M.Y., H.Z., and Z.Y. performed the search and interviews. H.L. advised on clinical knowledge of hypertension. L.X. analyzed the data and wrote the paper. All authors read and approved the final manuscript. 
Acknowledgements: We thank the China Health and Retirement Longitudinal Study (CHARLS) team for providing data. We also thank all members of the NHC Key Laboratory of Health Technology Assessment for providing assistance.

\section{References}

1. Wang Z, Chen Z, Zhang L, Wang X, Hao G, Zhang Z, et al. Status of hypertension in China: Results from the China Hypertension Survey, 2012-2015. Circulation 2018;137:2344-56. doi:10.1161/CIRCULATIONAHA.117.032380

2. Lu J, Lu Y, Wang X, Li X, Linderman GC, Wu C, et al. Prevalence, awareness, treatment, and control of hypertension in China: Data from 1.7 million adults in a population-based screening study (China PEACE Million Persons Project). Lancet 2017;390:2549-58. doi:10.1016/S0140-6736(17)32478-9.

3. Wu Y, Huxley R, Li L, Anna V, Xie G, Yao C, et al. Prevalence, awareness, treatment, and control of hypertension in China: Data from the China National Nutrition and Health Survey 2002. Circulation 2008;118:2679-86. doi:10.1161/CIRCULATIONAHA.108.788166

4. Li W, Gu H, Teo KK, Bo J, Wang Y, Yang J, et al. Hypertension prevalence, awareness, treatment, and control in 115 rural and urban communities involving 47000 people from China. J Hyperten 2016;34:39-46. doi:10.1097/HJH.0000000000000745

5. Zhou M, Wang H, Zeng X, Yin P, Zhu J, Chen W, et al. Mortality, morbidity, and risk factors in China and its provinces, 1990-2017: A systematic analysis for the Global Burden of Disease Study 2017. Lancet 2019;394:1145-58. doi:10.1016/S0140-6736(19)30427-1

6. Ettehad D, Emdin CA, Kiran A, Anderson SG, Callender T, Emberson J, et al. Blood pressure lowering for prevention of cardiovascular disease and death: a systematic review and meta-analysis. Lancet 2016; 387(10022): 957-67. doi:10.1016/S0140-6736(15)01225-8

7. Wang L, Kong L, Wu F, Bai Y, Burton R. Preventing chronic diseases in China. Lancet 2005;366:1821-4 doi:10.1016/S0140-6736(05)67344-8

8. Opinions on promoting the essential public health services gradually equalization. PRC Ministry of Health website. http://www.nhc.gov.cn/jws/s3581r/200910/fe1cdd87dcfa4622abca696c712d77e8.shtml? from=singlemessage. Updated October 2009. Accessed 27 Oct 2020.

9. Notice on inform national essential public health services in 2013. PRC Ministry of Health website. http://www.nhc.gov.cn/jczds/jslgf/201306/b035feee67f9444188e5123baef7d7bf.shtml. Updated June 2013. Accessed 27 Oct 2020.

10. Notice on inform national essential public health services in 2015. PRC Ministry of Health website. http://www.nhc.gov.cn/jws/s3577/201506/61340494c00e4ae4bca0ad8411a724a9.shtml. Updated June 2015. Accessed 27 Oct 2020.

11. Zhang D, Pan X, Li S, Liang D, Hou Z, Li Y, et al. Impact of the national essential public health services policy on hypertension control in China. Am J Hypertens 2018;31:115-23. doi:10.1093/ajh/hpx139.

12. Miaomiao T, Heng W, Xue Tao T, Kun Z, Xiao Juan Z, Xi C. Essential public health services' accessibility and its determinants among adults with chronic diseases in China. PLoS ONE 2015;10:e0125262.

13. Pan F, Wang H, Wang Z, Su C, Zhang J, Zhang B. Medical cost attributable to hypertension among Chinese middle and old aged residents in 2011 [in Chinese]. Wei Sheng Yan Jiu 2017;46:246-50. 
14. Bao-rong YF. Analysis on annual change of medical expenses for hypertensive inpatients with different types of health insurance. Chin Health Res 2012;15:406-8.

15. Xlong J-Y, Chen K-J, Xiong X-J. Analysis of the cost and influence factors urban hypertensive patients in China. Chin Health Econ 2010;29:81-3.

16. Zhao Y, Hu Y, Smith JP, Strauss J, Yang G. Cohort profile: The China health and retirement longitudinal study (CHARLS). Int J Epidemiol 2014;43:61-8. doi:10.1093/ije/dys203

17. Zhou BF. Predictive values of body mass index and waist circumference for risk factors of certain related diseases in Chinese adults-study on optimal cut-off points of body mass index and waist circumference in Chinese adults. Biomed Environ Sci 2002;15:83-96. doi:10.1046/j.1440-6047.11.s8.9.x

18. Caliendo M, Kopeinig S. Some practical guidance for the implementation of propensity score matching. J Econ Surv 2008;22:31-72. doi.:10.1111/j.1467-6419.2007.00527.x

19. Rosenbaum PR, Rubin DB. The central role of the propensity score in observational studies for causal effects. Biometrika 1983;70:41. doi:10.2307/2335942

20. Karan A, Yip W, Mahal A. Extending health insurance to the poor in India: An impact evaluation of Rashtriya Swasthya Bima Yojana on out of pocket spending for healthcare. Soc Sci Med 2017;181:83-92. doi:10.1016/j.socscimed.2017.03.053

21. Godard-Sebillotte C, Karunananthan S, Vedel I. Difference-in-differences analysis and the propensity score to estimate the impact of non-randomized primary care interventions. Family Pract 2018;36:247-51. doi:10.1093/fampra/cmz003

22. Tobin J. Estimation of relationships for limited dependent variables. Econometrica 1958;26:24-36.

23. Song Z, Hill C, Bennet J, Vavasis A, Oriol NE. Mobile clinic in Massachusetts associated with cost savings from lowering blood pressure and emergency department use. Health Aff 2013;32:36-44. doi:10.1377/hlthaff.2011.1392

24. Kirkland EB, Heincelman M, Bishu KG, Schumann SO, Schreiner A, Axon RN, et al. Trends in healthcare expenditures among US adults with hypertension: National Estimates, 2003-2014. J Am Heart Assoc 2018;7. doi:10.1161/JAHA.118.008731

25. Li X, Jan S, Yan LL, Hayes A, Chu Y, Wang H, et al. Cost and cost-effectiveness of a school-based education program to reduce salt intake in children and their families in China. PLoS ONE 2017;12. doi:10.1371/journal.pone.0183033

26. Chinese Preventive Medicine Association; Chinese Preventive Medical Association Heart Disease Prevention and Control Professional Committee; Chinese Medical Association Diabetes Society; Stroke Prevention and Control Professional Committee of Chinese Preventive Medical Association; Chinese Medical Association Health Management Branch; Chronic Disease Prevention and Control Branch of Chinese Preventive Medical Association; Hypertension Branch of China Association for Promotion of International Health Care Exchanges; China Community Health Association; Dongfeng Gu. Chinese guidelines for healthy lifestyle prevention of cardiovascular and metabolic diseases [in Chinese]. Chi J Prev Med 2020; 03: 256-77. doi:10.3760/cma.j.issn.0253-9624.2020.03.006

27. Liu YQ, Bai YN, Li HY, Li JS, Ji XH, Ren XW, et al. Study on trends of disease burden of hypertension in Jinchang Cohort [in Chinese]. Journal of Lanzhou University (Medical Sciences). 2015;41(06):39-43. doi:10.13885/j.issn.1000-2812.2015.06.007 
28. Iso H, Shimamoto T, Naito $Y$, Sato S, Kitamura A, lida M, et al. Effects of a long-term hypertension control program on stroke incidence and prevalence in a rural community in Northeastern Japan. Stroke 1998;29:1510-8. doi:10.1161/01.STR.29.8.1510

29. Dong X, Rao J, Ye Y, Pang M, Yang J, Wang H, et al. Trends and associated factors of hypertension among residents aged $\geq 15$ years in Guangzhou, China, 2004-2013. Iran J Public Health 2018;47(2):198-208.

30. Center for Health Statistics and Information. China Ministry of Health. An analysis report of national health services survey in China, 2013.

http://www.nhc.gov.cn/mohwsbwstjxxzx/s8211/201610/9f109ff40e9346fca76dd82cecf419ce.shtml. Updated 26 Oct 2016. Accessed 27 Oct 2020.

31. Dong Y, Qian Y, Wang XX, Dong MH. Economic burden of patients with hypertension or type 2 diabetes mellitus in Wuxi' communities [in Chinese]. Chin Health Serv Manage 2015;32:18-21.

32. Liu M, Li Y, Liu S, Wang W, Zhou M. Burden on blood-pressure-related diseases among the Chinese population in 2010. Chin J Epidemiol 2014;6:680-3. doi:10.3760/cma.j.issn.0254-6450.2014.06.014

33. Shane DM, Ayyagari P. Spillover effects of the affordable care act? Exploring the impact on young adult dental insurance coverage. Health Serv Res 2015;50:1109-24. doi:10.1111/1475-6773.12266

34. Einav L, Finkelstein A, Ji Y, Mahoney N. Randomized trial shows healthcare payment reform has equal-sized spillover effects on patients not targeted by reform. PANAS 2020;117: 18939-47.

doi:10.1073/pnas.2004759117

35. Fang W, Yong-Bin L, Xue D, Tao D. The National Essential Public Health Services project in China: Progress and equity. Chin J Health Pol 2013;5:9-14.

\section{Tables}

Table 1. Comparable characteristics between the two groups before and after PSM in 2011. 
Characteristics Before matching

$\begin{array}{lllllll}\text { Comparison } & \text { Treatment } & \mathrm{t}- & \mathrm{p}- \\ \text { value } & \begin{array}{l}\mathrm{v} \text { value } \\ \end{array} & & \text { Comparison } & \text { Treatment } & \begin{array}{l}\mathrm{t}- \\ \text { value }\end{array} & \begin{array}{l}\mathrm{p} \text { - } \\ \text { value }\end{array}\end{array}$

\begin{tabular}{|c|c|c|c|c|c|c|c|c|}
\hline Age $\geq 65$ & $28.92 \%$ & $46.61 \%$ & 6.62 & $<0.001$ & $47.49 \%$ & $46.61 \%$ & -0.24 & 0.811 \\
\hline Female & $45.62 \%$ & $45.80 \%$ & 0.06 & 0.951 & $47.83 \%$ & $45.80 \%$ & -0.55 & 0.581 \\
\hline Have a partner & $87.34 \%$ & $85.37 \%$ & -1.01 & 0.312 & $87.74 \%$ & $85.37 \%$ & -0.94 & 0.346 \\
\hline Farmer & $44.80 \%$ & $46.88 \%$ & 0.72 & 0.469 & $45.19 \%$ & $46.88 \%$ & 0.46 & 0.645 \\
\hline \multicolumn{9}{|l|}{ Education } \\
\hline $\begin{array}{l}\text { Elementary } \\
\text { school }\end{array}$ & $22.12 \%$ & $29.54 \%$ & 3.03 & 0.002 & $27.78 \%$ & $29.54 \%$ & 0.53 & 0.597 \\
\hline Middle school & $33.33 \%$ & $21.14 \%$ & -4.58 & $<0.001$ & $21.07 \%$ & $21.14 \%$ & 0.02 & 0.982 \\
\hline \multicolumn{9}{|l|}{$\begin{array}{l}\text { Household } \\
\text { income }\end{array}$} \\
\hline Low income & $26.97 \%$ & $25.20 \%$ & -0.69 & 0.490 & $26.15 \%$ & $25.20 \%$ & -0.29 & 0.768 \\
\hline Middle income & $25.27 \%$ & $23.85 \%$ & -0.57 & 0.571 & $24.19 \%$ & $23.85 \%$ & -0.11 & 0.914 \\
\hline High income & $24.76 \%$ & $22.22 \%$ & -1.03 & 0.305 & $23.98 \%$ & $22.22 \%$ & -0.57 & 0.571 \\
\hline Insurance & $93.57 \%$ & $97.02 \%$ & 2.56 & 0.011 & $97.36 \%$ & $97.02 \%$ & -0.28 & 0.781 \\
\hline $\begin{array}{l}\text { Rural } \\
\text { Residence }\end{array}$ & $38.00 \%$ & $41.46 \%$ & 1.23 & 0.218 & $42.01 \%$ & $41.46 \%$ & -0.15 & 0.882 \\
\hline $\mathrm{BMI} \geq 24$ & $65.72 \%$ & $61.52 \%$ & -1.52 & 0.128 & $63.01 \%$ & $61.52 \%$ & -0.42 & 0.677 \\
\hline $\begin{array}{l}\text { Not poor self- } \\
\text { reported } \\
\text { health }\end{array}$ & $64.52 \%$ & $65.31 \%$ & 0.28 & 0.776 & $65.04 \%$ & $65.31 \%$ & 0.08 & 0.939 \\
\hline
\end{tabular}

BMI: body mass index

Table 2. Impact of the NEPHSP on the outpatient and inpatient expenditure after PSM 


\begin{tabular}{|c|c|c|c|c|c|c|c|}
\hline & 2011 & 2013 & & & 2015 & & \\
\hline Inpatient & Mean (SD) & Mean (SD) & & & Mean (SD) & & \\
\hline \multirow[t]{2}{*}{ Comparison } & 979.61 & 2287.89 & & & 2888.91 & & \\
\hline & $(5840.30)$ & (9874.28) & & & (14059.57) & & \\
\hline \multirow[t]{2}{*}{ Treatment } & 1179.54 & 1988.70 & & & 1837.49 & & \\
\hline & (5247.45) & (8183.03) & & & (12068.14) & & \\
\hline \multirow[t]{2}{*}{ DID estimates } & & & Coefficient & $\mathrm{p}$-value & & & $p$-value \\
\hline & & & (SE) & & & & \\
\hline \multirow[t]{2}{*}{ Expected } & & & -138.35 & 0.586 & & -1072.02 & 0.068 \\
\hline & & & $(166.33 \%)$ & & & (586.76\%) & \\
\hline \multirow[t]{2}{*}{ Actual cost $>0$} & & & -129.98 & 0.583 & & -426.40 & 0.061 \\
\hline & & & $(236.60)$ & & & $(227.27)$ & \\
\hline \multirow[t]{2}{*}{ Actual cost } & & & -183.53 & 0.582 & & -599.73 & 0.059 \\
\hline & & & $(333.65)$ & & & $(317.82)$ & \\
\hline Outpatient & Mean (SD) & Mean (SD) & & & Mean (SD) & & \\
\hline \multirow[t]{2}{*}{ Comparison } & 204.13 & 387.25 & & & 408.74 & & \\
\hline & (1411.47) & (3535.29) & & & (2726.68) & & \\
\hline \multirow[t]{2}{*}{ Treatment } & 84.89 & 248.89 & & & 555.73 & & \\
\hline & $(426.71)$ & (1014.85) & & & (6030.02) & & \\
\hline \multirow[t]{2}{*}{ DID estimates } & & & Coefficient & $\mathrm{p}$-value & & & $p$-value \\
\hline & & & $(\mathrm{SE})$ & & & & \\
\hline \multirow[t]{2}{*}{ Expected } & & & -138.35 & 0.406 & & 147.00 & 0.377 \\
\hline & & & (166.33) & & & (166.33) & \\
\hline \multirow[t]{2}{*}{ Actual cost $>0$} & & & -53.04 & 0.400 & & 58.04 & 0.383 \\
\hline & & & $(62.97)$ & & & $(66.54)$ & \\
\hline \multirow[t]{2}{*}{ Actual cost } & & & -74.09 & 0.398 & & 81.60 & 0.384 \\
\hline & & & (87.69) & & & (93.81) & \\
\hline
\end{tabular}

\section{Figures}




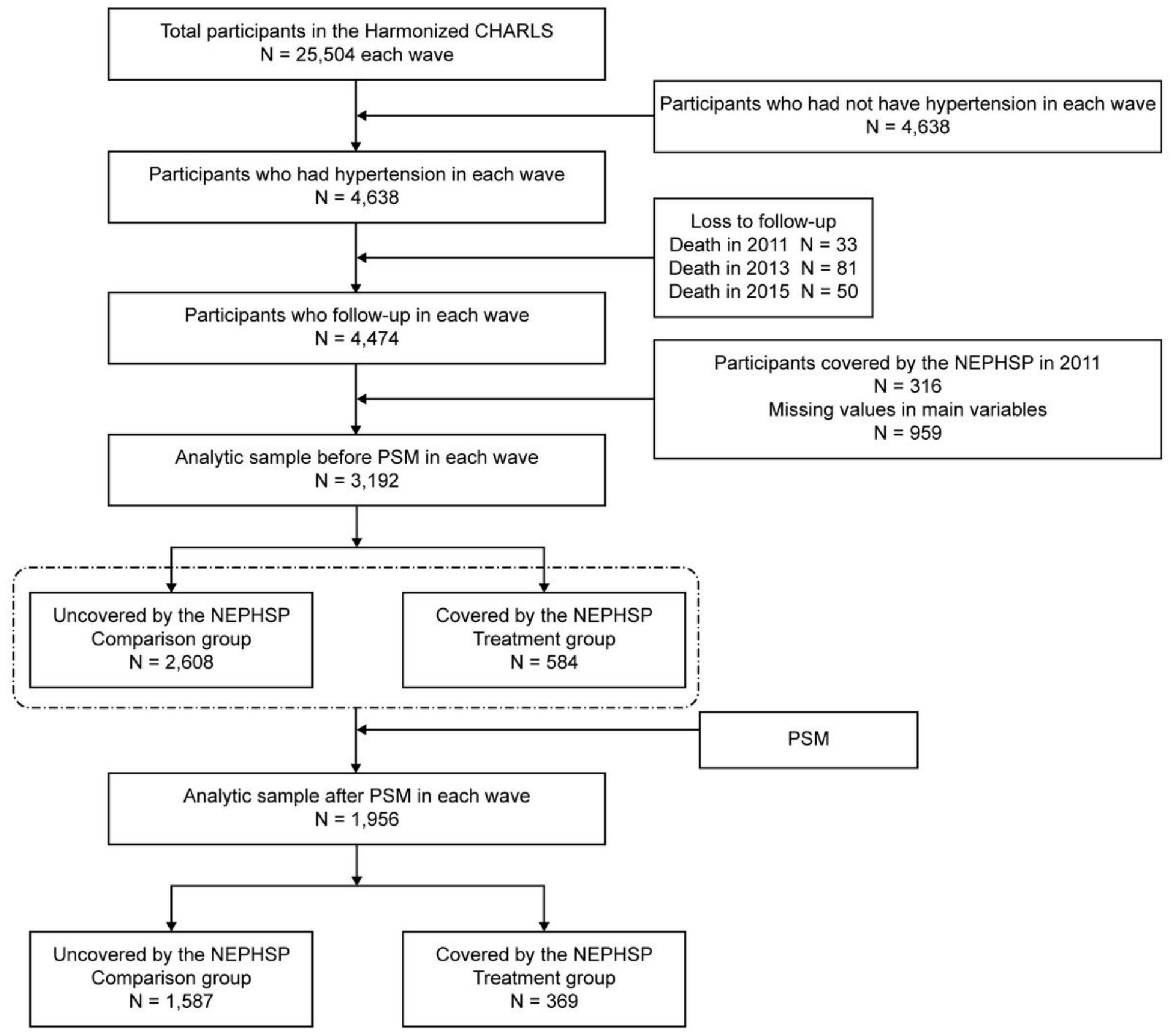

\section{Figure 1}

Flow chart of the participants. 


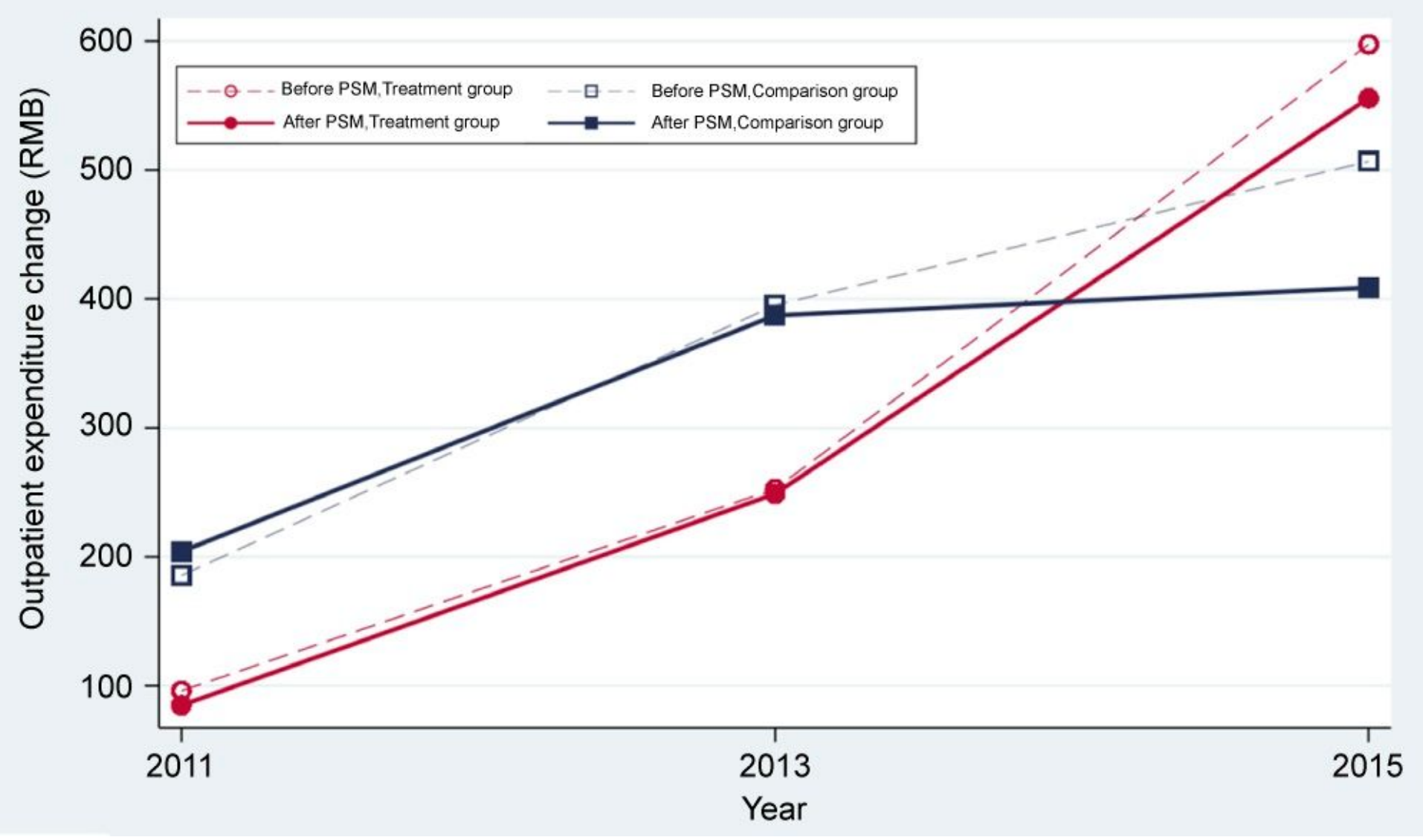

Figure 2

Comparison of outpatient expenditure of the treatment and comparison groups before and after PSM (RMB).

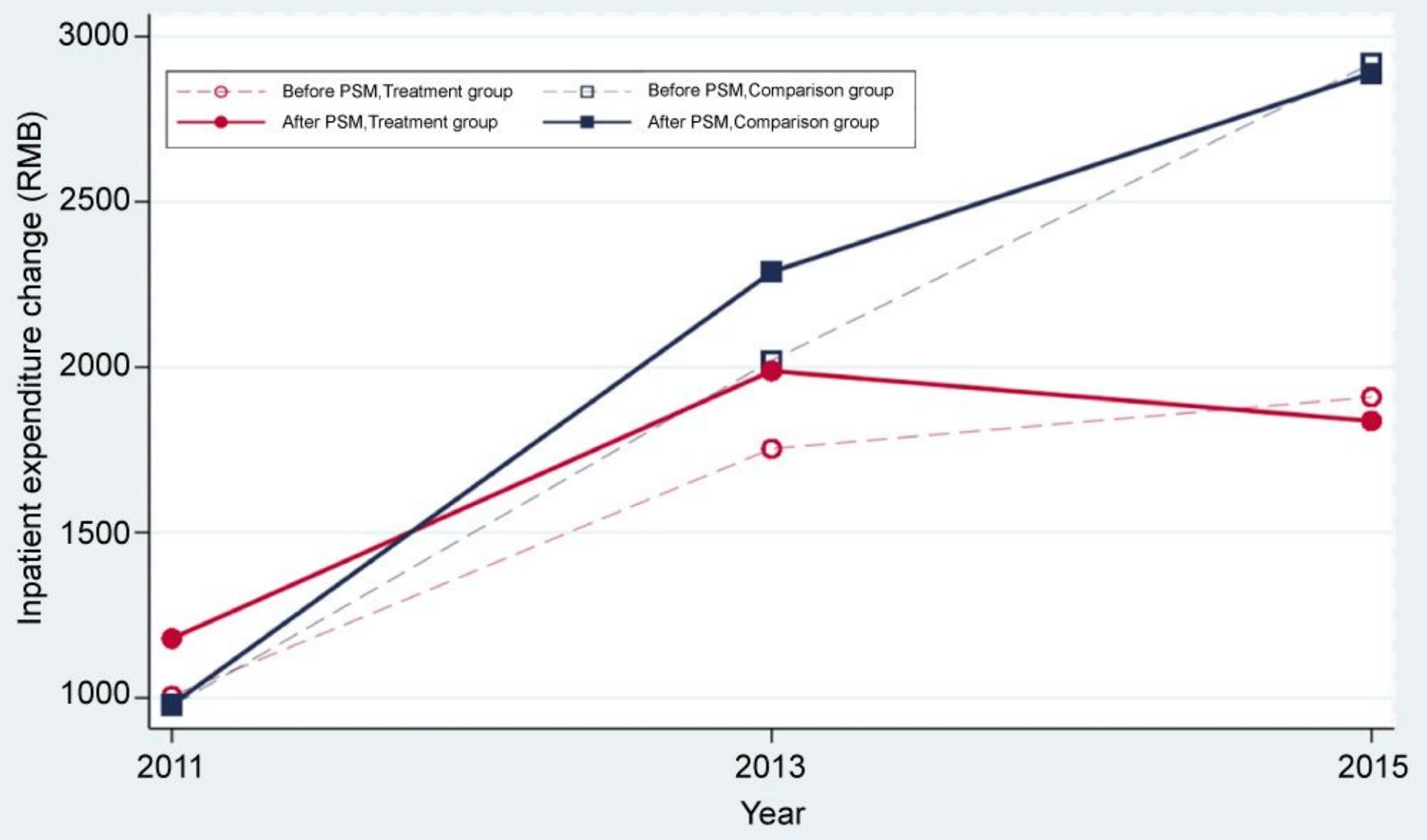




\section{Figure 3}

Comparison of inpatient expenditure of treatment and control comparison before and after PSM (RMB).

A

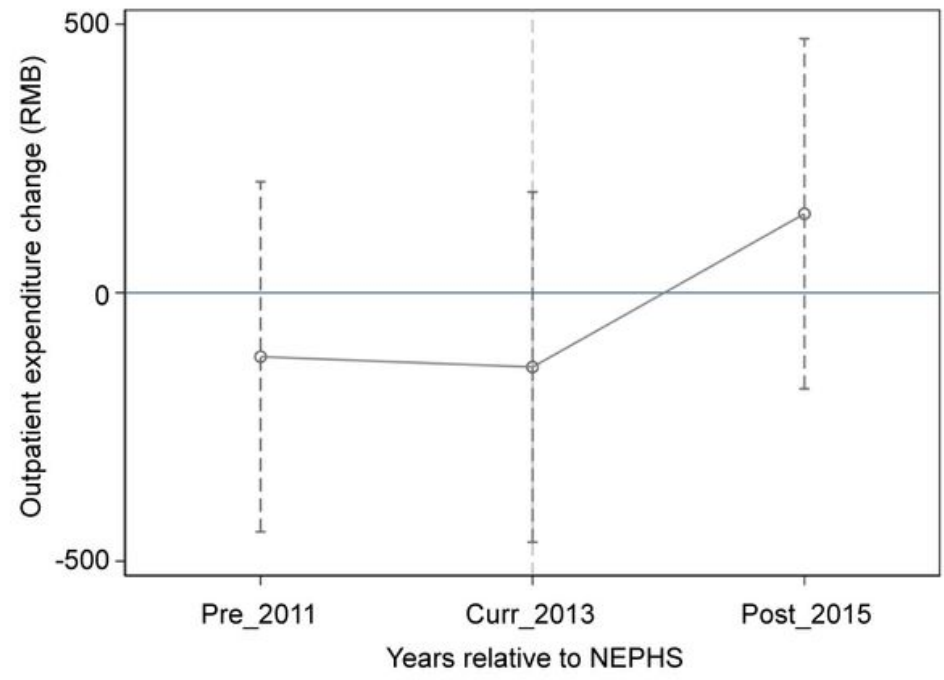

B

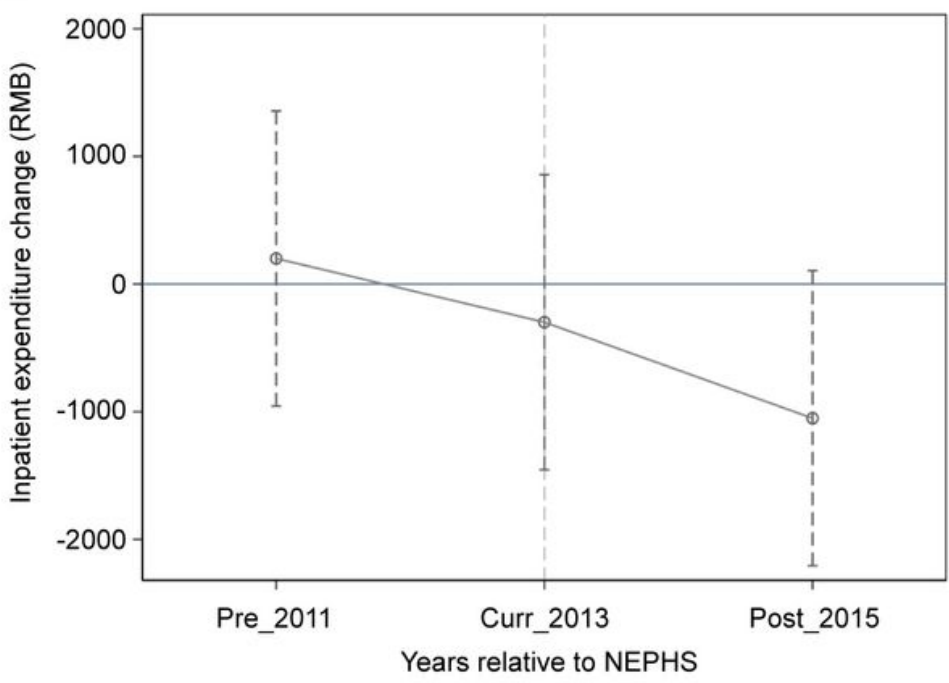

Figure 4

A. Trends in outpatient expenditure after PSM (RMB), comparison of outpatient expenses between the comparison group and the treatment group in $2011(p=0.473), 2013(p=0.406)$, and $2015(p=0.377)$, respectively. B. Trends in inpatient expenditure after PSM (RMB), comparison of inpatient expenses between the compari-son group and the treatment group in 2011 ( $p=0.735), 2013(p=0.612)$, and 2015 ( $p=0.075)$, respectively.

\section{Supplementary Files}

This is a list of supplementary files associated with this preprint. Click to download.

- AdditionalFigure1.tif

- AdditionalFigure2.tif

- AdditionalFigure3.tif

- AdditionalFigure4.tif

- AdditionalTables.doc 